International JOURNAL OF MULTidisciplinary RESEARCH AND ANALysis

ISSN(print): 2643-9840, ISSN(online): 2643-9875

Volume 05 Issue 01 January 2022

DOI: 10.47191/ijmra/v5-i1-06, Impact Factor: 6.072

Page No.- 44-52

\title{
Senior Citizen information System
}

\section{April Rose A. Zaragosa ${ }^{1}$, Bella Gertrude B. Alpasan ${ }^{2}$, Mary Jane V. Esimos ${ }^{3}$, Sharra Mae B. Fernandez ${ }^{4}$,} Audrey Karyl P. Maligang ${ }^{5}$, Sheila Mae S. Pagayonan ${ }^{6}$.

1,2,3,4,5,6 Northern Iloilo Polytechnic State College, Estancia, Iloilo

ABSTRACT: This developmental-descriptive research sought to design and developed a computer-based system, to be known as the Senior Citizens Information System, to provide real-time information dissemination among senior citizen members in the Municipality of Batad, lloilo pertaining to their membership status and monetary assistance monitoring. The Rapid Application Development model was employed as the SDLC in the development of the system product. More so, the three-tier architecture was used as the architectural model. There were 120 senior citizens as user-respondents and five IT experts for evaluation. The system product was evaluated using a researchers-made survey instrument to determine if level of usability and performance. Results of the investigation shows that the system product was perceived as very good with its level of usability as well as its performance.

KEYWORDS: Computer- based System, Information System, Rapid Application Development, Senior Citizen

\section{I.INTRODUCTION}

Today, information system, an integrated set of components for collecting, storing, and processing data and for providing information, knowledge, and digital products. Other organizations rely on information systems to carry out and manage their operations, interact with their clients. Information systems are used to run interorganizational supply chains and electronic markets.

As information systems enabled more diverse human activities, they exerted a profound influence over society. These systems quickened the pace of daily activities, enabled people to develop and maintain new and often more-rewarding relationships, affected the structure and mix of organizations and influenced the nature of work. Information and knowledge became vital economic resources. (https://www.britannica.com/topic/information-system)

Apparently, the Senior Citizen's Office of Batad, lloilo is using the traditional manual system in all transactions especially in the management of information to its member. Due to their manual way of keeping important records in the office and transactions, some problems were encountered that need to be solved. They are having difficulty in searching for individual records, encountering loss of data, having record misplacement's retrieving the past records. On the part of the senior citizens, there are times where the information intended for them are not received especially about meetings and in releasing of the senior citizen quarterly allowances. These reasons and problems lead to the development of a computer-based system that can ease the operations of their office.

In this study, the researchers focused on the transformation of the current manual system used by the Senior Citizens Office at Batad, lloilo in giving the information to the members.

The system approach (Input-Process-Output System) is used to describe the Conceptual Framework of the study. The procedures started with the inputs, software development as a process and product evaluation as output.

The inputs are the essential to the development of the system in order to produce relevant output of the information.Thus, the input in this study included the Senior Citizen Member's Detailand type of event.The data inputs were securely processed and managed by the Senior Citizen Information System for the better output of information. The outputs of the study were the levels of usability and performance of the developed system.

Figure 1 shows the conceptual model of the study. 


\section{Senior Citizen information System}

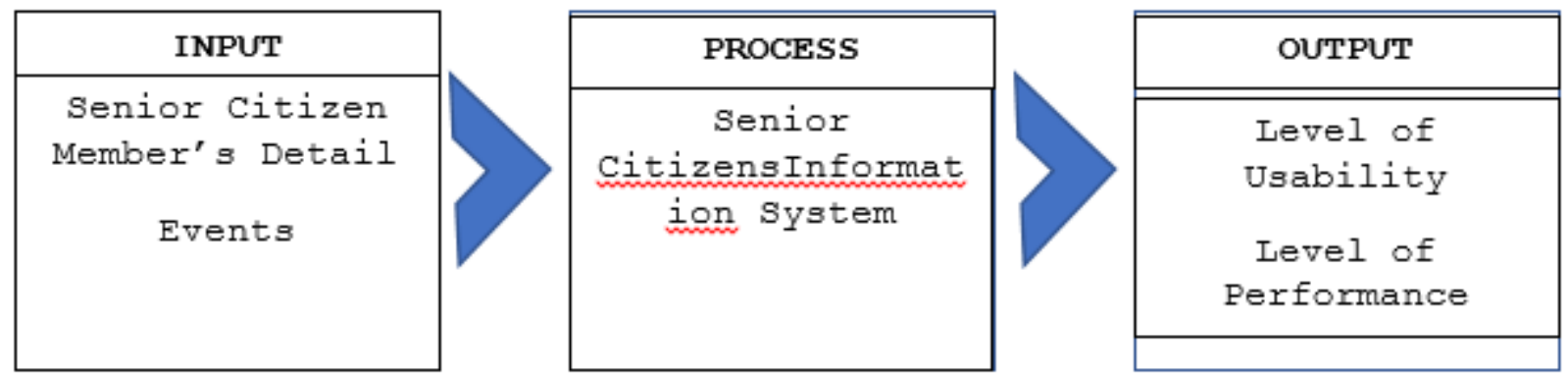

Figure 1. The Conceptual Model of the Study

The Senior Citizens Information System is a computer-based system aimed to efficiently manage the activities in the senior citizens office at the municipality of Batad, Iloilo.

Specifically, the study sought to:

1. Designed and developed an information system that provides real-time information for the senior citizens events.

2. Determine the level of usability of the developed system as perceived by the senior citizens of Batad, lloilo in terms of learnability, understandability and operability.

3. Evaluate the performance of the developed system as perceived by the expert evaluators in terms of time behavior and resource utilization.

The study is mainly concerned with the dissemination of information such as event and quarterly allowances of the members at Batad, lloilo. The subjects of the study were the registered members of the senior citizens in the said municipality. This study was conducted at the Municipality of Batad, lloilo consisting of twenty four (24) barangays. The study was conducted in the year 2018. It consist of two major components namely the development of the system prototype and the evaluation of the system product. For the development of the system prototype, the Rapid Application Design model was employed as the System Development Life Cycle.

In the evaluation of the system product, the researchers conducted a survey to solicit feedbacks from 125 respondents on their perception of the system product based on pre-defined evaluation criteria. The Mean statistic was used to statistically interpret the result of the responses.

\section{METHODOLOGY}

\section{Research Design}

The research designs used by the researchers were developmental and descriptive. Developmental research is a method to investigate patterns and sequences of growth and change as a function of time (Bueno, 2016). It is used in this study to develop an efficient and complete functional computer-based system.

Descriptive research design refers to the type of research question, design, and data analysis that was applied to a given topic. Descriptive research design is a scientific method which involves observing and describing the behavior of a subject without influencing it in any way (Bueno, 2016). In line with this study, the survey method was used to collect self-report data of thestudy; the participants were described as the objectives of the study. The purpose of the survey is to gather personal data about the existing performance of the developed system based on the specific indicators.

\section{Software Development Life Cycle (SDLC)}

In this study, Rapid Application Development (RAD) was used as the SDLC model. The RAD, described the method of software development which heavily emphasizes rapid prototyping and iterative delivery. The RAD model was, therefore, a sharp alternative to the typical waterfall development model, which often focuses largely on planning and sequential design practices.

Utilizing a Rapid Application Development method, researchers can aggressively utilize knowledge and discoveries gleaned during the development process itself to shape the design and or alter the software direction entirely.

The RAD generally follows a cyclical process that includes four basic steps or phases which were: Planning Requirements, User Design, Rapid Construction, Cutover/Transition or Implementation. Each step/phase, the researcher performs specified activity led to develop a system. Figure 2 shows the RAD Model. 


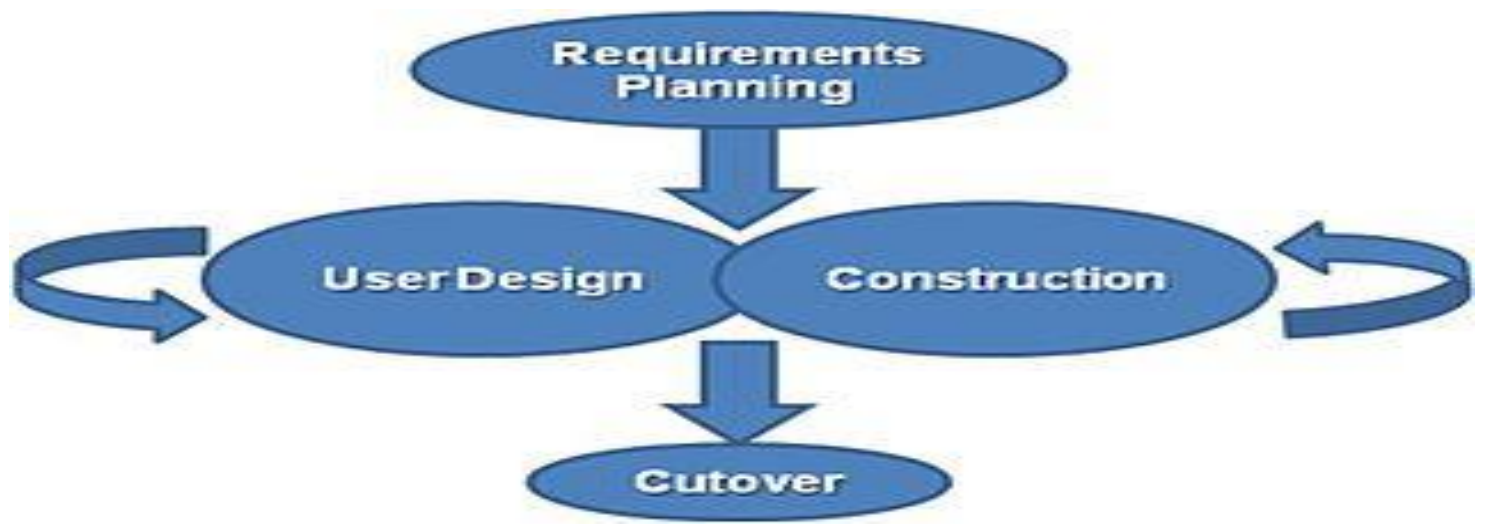

Figure 2. The Rapid Application Development Model

\section{Requirements Planning Phase}

During the initial stage, the researchers and users come to a rough agreement on project scope and application requirements, so that future stages with prototyping can begin.

It started with the meeting between the Senior Citizen's officers and the researchers. It was initiated by discussing of the process and establishing the agreement of the objectives for the development project in general and final result of the particular developed system.

The researchers have initially conducted the Requirements Planning phase and had able to perform the following tasks:

1. Conduct of Environmental Scanning. To be able to understand the current situation at the Office of the Senior Citizens with their activities involved, the researchers conducted a physical observation at the Office to have first-hand information that their office needs to do in order to make their manual storing of the data were each of the member secured. The researchers also conducted face to face interview with the senior citizen's officers on the manner of how the process of informing every members of the Senior Citizens Organization. The conduct of the task provided the researchers a clearer picture of the current situation.

2. Requirements Definition. The project's scope was defined in this task. The functionality of the system was expressed in terms of the business processes and the data that the system supported. The requirements definitions were expressed as functional requirements and non-functional requirements.

For the functional requirements, the project's scope was only limited within the activities of the Office on how they spread the information from the high-level of Senior Citizens Offices down to towns offices down to each member or each of the Senior Citizens in order to receive an information for their quarterly allowances. Simple interface design, easy to use, color scheme, font sizes. For the non-functional requirements, the user was able to improve the traditional way of spreading the information just a click away and that the output wasable to improve their System.

3. Finalization of Requirements. The requirements in the previous task were properly documented that serves as the basis of the development of the various functionalities of the developed system. It was presented to the senior citizens officials for their approval to proceed with the project.

\section{User Design (UD) Phase}

The objectives of the User Design phase are (i) to study the business processes related $\mathrm{w} /$ the developed system area; (ii) to analyse in detail business activities associated with the previous phase; (iii) to the developed system structure in terms of the automated and manual functions that comprise the system; (iv) the developed screen layouts for the most important automated functions; ( $v$ ) to select the appropriate construction approach for the system.

Design phase is to specify the components for this transformation, so that each component is also a transformation function. It seeks to develop detailed specifications that emphasize the physical solutions to the user's information technology needs. It contained functional diagrams, screen layouts, business rules, business process diagrams and ERD with a full data dictionary.

The UD phase produces a detailed system area model, an outline system design, and an implementation plan. The following tasks were conducted under this phase.

1. Detailed System Area Model. In order to produce the detailed activities for the developed system area, the researcher presented the developed system to the Senior Citizen Officers a thorough discussion on the specific functional components of the developed system. The detailed system area model wascompleted; it was possible to refine the scope to ensure that the critical functions were delivered in the required time of frame. 


\section{Senior Citizen information System}

2. Data Model. After the detailed system area model was known, the next task was analysing the business data that the developed system needs.

However, the analysis of the business data was implemented through the use of the Entity Relationship Diagram (ERD). An entity relationship diagram (ERD) shows the relationships of the entity sets stored in the database. An entity in this context was the component of data. In other words, ER diagrams illustrated the logical structure of the databases. For the developed system, there were three entities made. The MEMBER entity, INFORMATION entity and EVENT entity. Relationships were set between among these entities. Thus, the following relationships were defined. One and only one member of the Senior Citizens in Batad, lloilo received one too many information. The message contains one and only one Event which allows one too many information to the members. Figure 3 shows the ERD model.

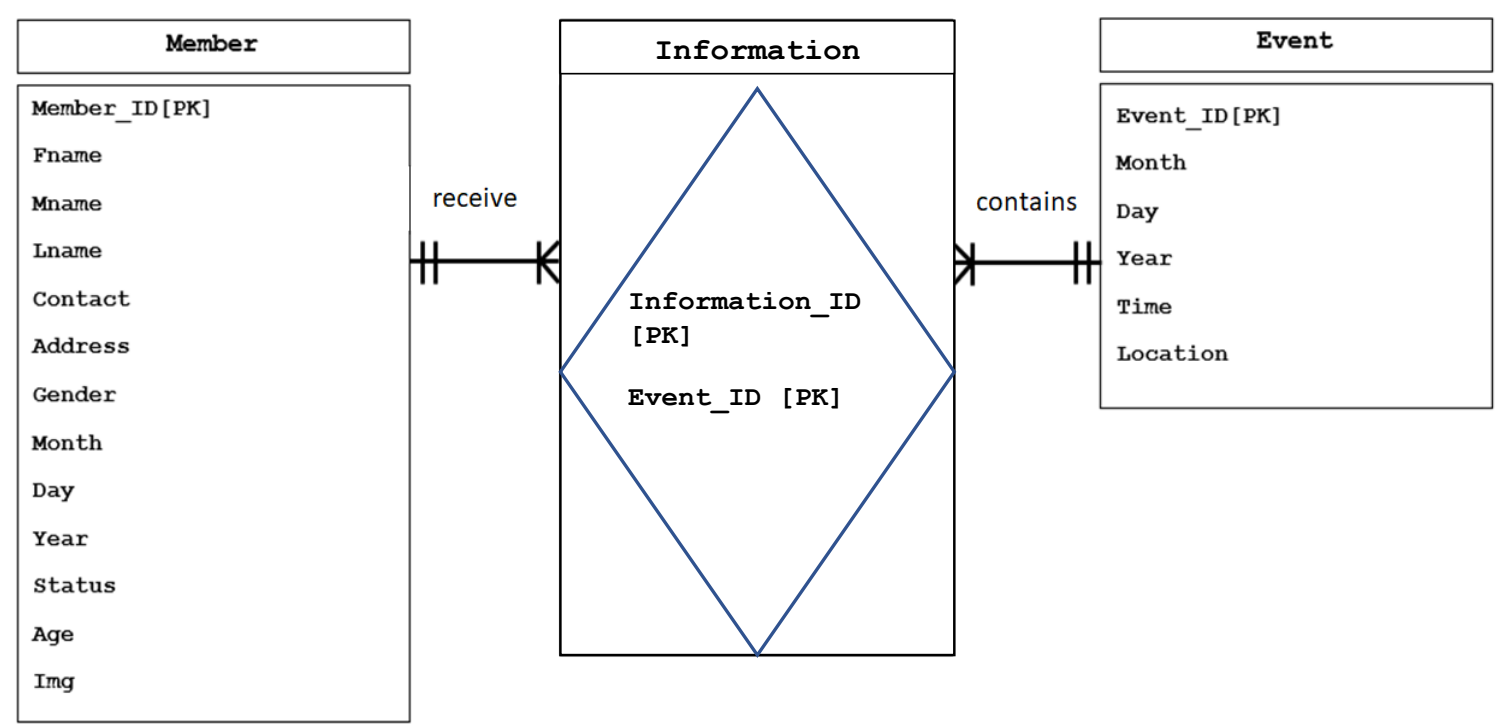

Figure 3. The Entity Relationship Diagram of the Developed System.

3. Process Model. The design that emerged reviewed by the researchers. The consistency of the analysis and design confirmed via interaction analysis and prototyping. By interaction analysis, the interactions between functions and data was analysed to be able to identify missing/ extraneous function. Through this, it shows the process model that describes business processes, the activities that people do. The process model was developed for the as-is system and/or the to be system. To show this process model the researcher described data flow diagramming, one most used process modelling techniques. The process model or data- flow diagram (DFD) was the graphical representation of the "flow" of data through an information system. DFDs also were used for the visualization of data processing (structured design). On a DFD, data items flow from an external data sources or an internal data store to an external data sink, via an internal process.

This makes use of the information and graphics to represent the process. The process shows the tasks or activities done by the system. Each process transforms inputs into outputs. The usefulness of this model extends beyond describing the software processes. There were two external agents involve in the process of this developed system. These were the administrator and the members.

The administrator who directly uses and operates the system, the one who receives and retrieves the requested information, has the full authority to use the developed system such as adding the member's information. Through this developedsystem, the office of the Senior Citizens can speed up the transaction and lessens the time in retrieving the member's record and other information needed.

The other external agents were the members. For the member's part, they can receive updated information or announcement through SMS Notification; they do not physically need to go in the office to get such nevertheless of taking their quarterly allowances. 


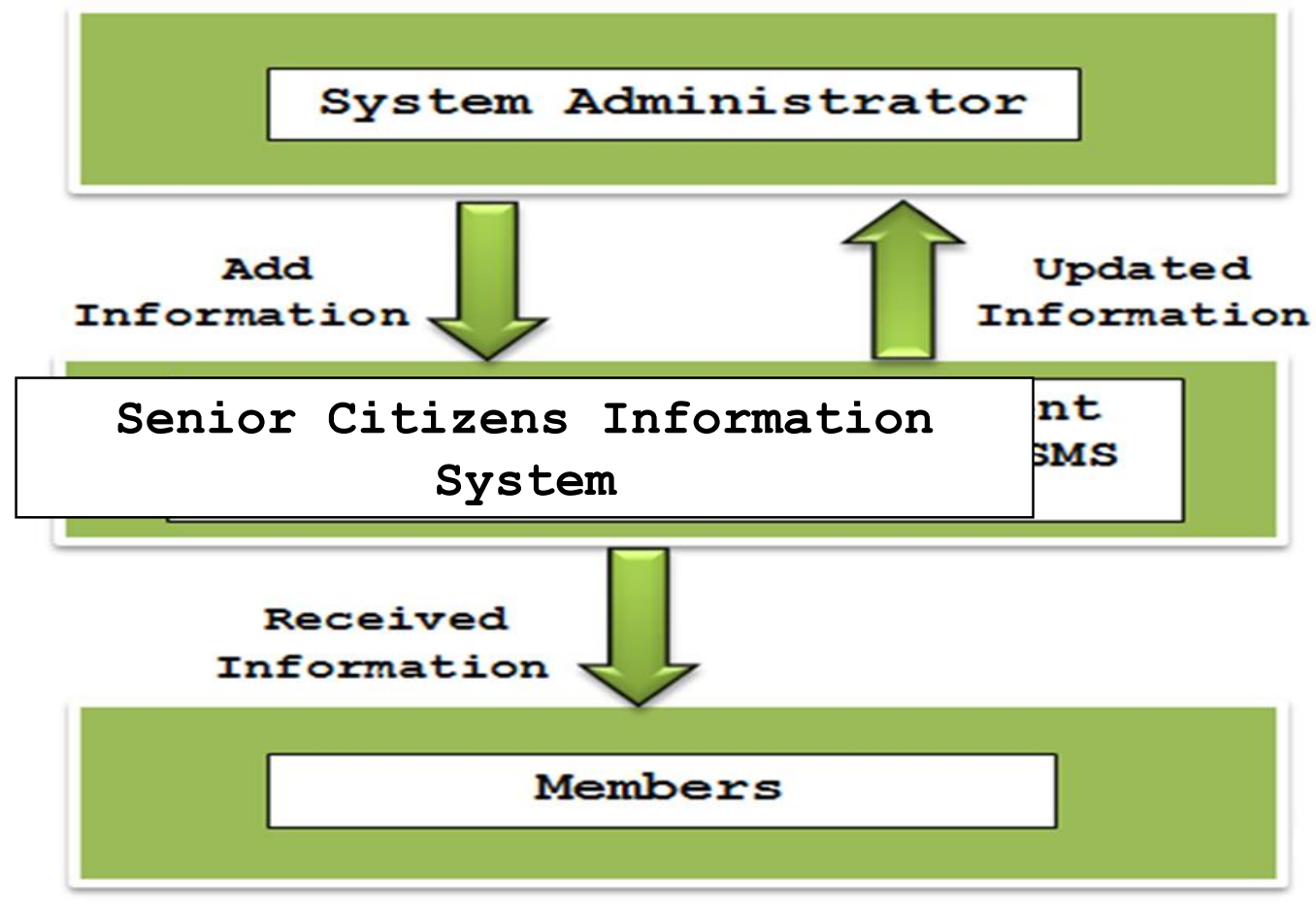

Figure 4. The Context Data Flow Diagram of the Developed System

4. Logical Architecture Design. A structural design that gives as much detail as possible without constraining the architecture to a particular technology or environment.

Through this, it showed that the Logical Architectural Design is one of the important documents that show the hardware, software and networks environments of the system. The developed system used tree-tier architecture. The researchers' designs a three-tier architecture, in which the functional process logic, data access, computer data storage and user interface were developed and maintained as independent modules on separate platforms.

The application logic was a three-tier architecture that allows any one of the three tiers to be upgraded or replaced independently.

In the presentation-tier, it serves as the topmost level of the application. The presentation tier displays information such as client interface of the developed Senior Citizens Information System in order for the user to communicate/access directly.

The next tier is the application tier or sometimes it can be the business logic, logic tier, or middle tier. This logical tier is pulled out from the presentation tier and, as its own layer, it controls an application's functionality to the application server of the developed system and at the same time in performing detailed processing through the developed system.

Finally, the data tier includes the data persistence mechanisms as MySQL server for the developed system and the data access layer that encapsulate the persistence mechanisms which exposes data to the senior citizens. This tier provides a data access layer to the application tier for the data to be stored in the said server.

5. Physical Network Topology. The final task in the UD phase was to present a model that showed physical network topology that visualizing the communication scheme of physical networks and its networks arrangement.The physical network topology depicted the placement of the components in the network. It showed the configuration of the cables, computers and other devices.

The developed system was using the client-server. The administrator is responsible to administer the system.

\section{Rapid Construction Phase}

Construction phase focused on program and application development task similar to the software development life cycle(SDLC). In RAD, however, users continued to participate and can still suggest changes or improvements as actual screen or reports was developed. Its tasks were programming and application development, coding, unit integration and system testing.

The objectives of the Rapid Construction stage were (i)to complete the detailed design of the developed system; (ii) to create and test the software that implements the developed system; (iii) to generate a system that operates an acceptable level of performance; (iv) to prepare documentation necessary to operate the developed system; (v) to design, develop, and test the required transition software and; (vi) to perform the steps necessary to prepare for the conversion of the system to production status. 


\section{Senior Citizen information System}

The design of the developed system was initially described in the UD stage, completed in the RC stage, and application software to implement that design was developed and tested. An activity to prepare for the transition of the system and the production status was also performed. The tasks of the RC stage are:

1. Preparation of the Rapid Construction. The development environment was finalized including workstation and workspace for the system developers, and the CASE software for their use. Additionally, the database was designed based on the preliminary data structure developed in the UD stage.

Finally, the testing strategy for the developed system were completed and the acquisition of facilities necessary to operate the developed system after it was constructed and initiated. The researchers make used of their personal laptop computer on the development of the system. Additionally, the MySQL for the database, vb 6.0language and windows operating system development environment. Installing this application package allowed the researcher to develop and test the system prototype in the local machine. For the SMS components, the researcher employed with the use of the Globe Tattoo Broadband USB stick. The device GSM-ready which means, it is capable for SMS related activities.

2. Construction of the System Prototype. The detail definition of the design of each function was completed, based on the requirements of the future end users. Software to implement the automated function was developed and tested.

3. Testing and Evaluation. This task involved the developed the necessary test data which was verified the operational capacity of the system. This data was used during the integration, system and acceptance test. Documentation explaining how the system was operated by users and computer operations personnel produced.

The developed system was undergone the series of evaluation by the expert on the field of the study and the Senior Citizens officer-in-charge as the user. After the testing, the researchers provided the researcher's made survey questionnaire that was created on ISO/IEC 25010 Software Quality Model to the respondents to allow them to evaluate user's experience which includes the usability, performance, time behavior and resource utilization of the system.

The result of the evaluation was part of the improvement of the process of the developed system. This research study utilized questionnaire to aim the user's level of experience and the overall functionality of the system.

In the study, the researchers identified two groups of users who evaluated the system. The first group was composed of five (5)experts on their field of the study and the second group was composed of one hundred twenty(120)senior citizens.

Table 1. Actual Distribution of Software Evaluators/Respondents.

\begin{tabular}{|l|l|l|}
\hline Type of Respondents & No. of Evaluators & Percentage \\
\hline Expert Evaluators & 5 & $4 \%$ \\
\hline Senior Citizens & 120 & $96 \%$ \\
\hline Total & $\mathbf{1 2 5}$ & $\mathbf{1 0 0 \%}$ \\
\hline
\end{tabular}

A researcher made survey questionnaire was administered by the evaluators after testing the product. A 5-point Linker scale comprising of 1 as poor and 5 as very good was used. The researchers made survey questionnaire was subjected to content validation by three members of the panel of experts in their field of information technology to help the researcher's identity whether the developed system meets the user's requirement and satisfaction. To statistically compute whether the developed system passes the evaluation criteria, the Mean statistics was applied.

The Mean has computed as:

$$
\bar{X}=\frac{\sum x}{n}
$$

Where $\bar{X}$ is the mean

$\sum x$ Is the summation of individual raw score

$\mathrm{N}$ is the total number of populations

The obtained mean score were interpreted using the following verbal descriptions:

$\begin{array}{cl}\text { Mean Score } & \text { Description } \\ 4.21-5.00 & \text { Very Good } \\ 3.1-4.20 & \text { Good } \\ 2.61-3.40 & \text { Average } \\ 1.81-2.60 & \text { Fair } \\ 1.0 \quad-1.80 & \text { Poor }\end{array}$




\section{Senior Citizen information System}

4. Finalization of the Developed System Product. After testing data of the system model, feedbacks coming from the users, more gathered and would become basis for system improvement. However, to improve the system the revisions must only up to three major chances, so that the project timeframe would not be drag by excision revisions. After the third major revisions, the final system product would be presented for the acceptance and would become ready for deployment.

\section{Cutover Phase}

The cutover phase resembles the final tasks in the SDLC implementation phase, including data conversion, testing, the changeover to the new system, and user training. Compared with traditional methods, the entire process was compress. As a result, the new system was built, delivered, and placed in operation much sooner.

The developed systemin the RC stage becomes operational in the TR stage. At this time, the developers prepared existing data for the new system and were trained users to operate the new application. They provided support to resolve any problems that arise immediately after the application becomes operational.

\section{RESULTS AND DISCUSSION}

\section{Level of Usability of the Developed System in terms of Learnability, Understand ability, and Operability}

Table 2 presented the mean score on evaluating the usability of the Senior Citizens Information System in terms of learnability, understand ability, and operability of the information provided to the clients. Usability refers to the degree in which a system can be used by specified users to achieve the specified goals. Learnability is the capability of the system to enable the user to learn its application quickly. Understand ability is the capability of the system product to enable the user to understand whether the system is suitable, and how it can be used for particular tasks and conditions. Operability is the degree to which a product or a system has attributes that make it easy to operate and control.

Based on the respondent's feedbacks, the level of usability of the developed system was 4.62 which interpreted as "Very Good"; Learnability had a computed mean of 4.62 interpreted as "Very Good"; Understand ability had a computed mean of 4.63 interpreted as "Very Good"; and Operability had a computed mean of 4.61 interpreted as "Very Good."

Table 2. Respondents Feedbacks as to the Level of Usability of the Developed System in terms of Learnability, Understand ability, and Operability

\begin{tabular}{|c|l|l|}
\hline Implementation Indicators & Mean & Verbal Interpretation \\
\hline Level of Usability & 4.62 & Very Good \\
\hline Learnability & 4.62 & Very Good \\
\hline Understand ability & 4.63 & Very Good \\
\hline Operability & 4.61 & Very Good \\
\hline
\end{tabular}

Legend: 1.00 - 1.80 (Poor); 1.81 - 2.60 (Fair);

2.61 - 3.40 (Average); 3.41 - 4.20 (Good);

$4.21-5.00$ (Very Good)

Performance of the Developed System at perceived by expert evaluators in terms of Time Behavior and Resource Utilization Table 3 presented the evaluation of the expert to the developed system. The table showed the mean score voted by the experts in terms of time behavior and resource utilization. Performance refers to the amount of work accomplish by the computer system. Time behaviour characterizes response times for given thruput, i.etransaction rate. Resource utilization characterizes resources used, i.e. CPU, memory, HDD and Network.

The total mean performance of the developed system was 4.41 which interpreted as "Very Good". In terms of time behavior the developed system had a computed mean of 4.32 being interpreted as "Very Good" and resource utilization had a computed mean of 4.50 which is interpreted as "Very Good".

Table 3. Performance of the Developed System at perceived by expert evaluators in terms of Time Behavior and Resource Utilization

\begin{tabular}{|l|l|l|}
\hline Implementation Indicators & Mean & Verbal Interpretation \\
\hline Performance & 4.41 & Very Good \\
\hline Time Behavior & 4.32 & Very Good \\
\hline Resource Utilization & 4.50 & Very Good \\
\hline
\end{tabular}

Legend: 1.00 - 1.80 (Poor); 1.81 - 2.60 (Fair);

2.61 - 3.40 (Average); 3.41 - 4.20 (Good);

4.21 - 5.00 (Very Good) 


\section{Senior Citizen information System}

\section{CONCLUSION}

The Senior Citizens Information System was a system consists of information of the Senior Citizens that was stored in a database. Their allowances were monitored and they were barely informed if there was an upcoming event. Specifically, the study was integrated the following objectives:

Designed and developed an Information System that is able to provide real-time information for the Senior Citizens events.

Determined the level of usability of the developed system at perceived by the senior citizens of Batad, Iloilo in terms of learnability, understandability and operability of the system and the information provided.

Evaluated the performance of the developed system as perceived by the expert evaluators in terms of time behavior and resource utilization.

Developmental method of the research was employed by the researcher and RAD as the model of the Software Development Life Cycle (SDLC) was used to design the Senior Citizens Information System. The researchers used mean to determine the level of usability and performance of the developed system.

The researchers were able to arrive at these conclusions based on the findings of the study.

The level of usability of the developed system was interpreted as "Very Good" in all the implementation indicators including the learnability, understandability and operability. This means that the respondents were satisfied and they can use the system as easy to use. The respondents learn its application quickly. It enables the user to understand and the information was clear. Its attributes were easy to operate and control.

The performance of the developed system was interpreted as "Very Good"in all its implementation indicators as the time behavior and resource utilization. This simply shows that the developed system responses time for given thru put transaction rate. The response of the system is excellent and it allows quick retrieval of stored information. The system can be installed in a low to mid-range computer system based on CPU frequencies. Lastly, it can run with standard physical memory.

From the findings and conclusions of the study, the following recommendations were strongly suggested:

For the senior citizens, should cooperate and provide the needed information to the system in order to receive an important notification coming from the developed system.

The administrator should maintain and update the systems which help to maximize its potential and improve its time behavior and resource utilization. Also, conducted training before using the developed system for the familiarization especially during data entry of important inputs for the developed system to work.

For future researchers, upgrade the developed system in to an SMS. Be sure it could lessen the system lag.

\section{REFERENCES}

1) Bueno, David Cababaro (2016) research and descriptive design retrieved from the book: Educational Research Writing made easy Quezon City: Great Books Trading

2) Garry Boy Sotto (2014 February 11) E-Reklamo: A Web- based and SMS-Based Barangay Complaint w/ Analytics Retrieved from https://prezi.com/q-4ptpfdfnvf/e-reklamo-a-web-based-and-sms-based-barangay-complaints-wit/

3) GEVEROLA, DANILO L. JR. and UGSANG, JOSHUA B. (May 2018) SENIOR CITIZEN WEB-BASED PROFILING SYSTEM Retrieved from https://www.scribd.com/document/380413323/Senior-Citizen-Web-based-Profiling-System

4) https://www.techopedia.com/definition/24275/short-message-service--sms What does Short Message Service (SMS) means

5) Martin Pielot, Karen Church and Rodrigo de Oliveira (September 2014) mobile phone notifications Retrieved from: //www.ic.unicamp.br/ oliveira/rssdoc/MHCl2014_An-in-situ-study-of-mobile-phonenotifications.pdf?utm_source=rss\&utm_medium=

6) Pvrtechnologies Nellore ( 2015, December 19)citizen services management system Retrieved from https://www.slideshare .net/PvrtechnologiesNellore/31citizen-services-management-system

7) Rosalyn P. Reyes, Evelyn C. Samson and Alvin V. Nuqui (2015).Senior Citizen Management System Sms based Retrieved from http://wjmcr.com/WJMCR Vol.\%201,\%20No.\%202, \%20June\%202015/MANAGEMENT.pdf

8) Shelly, Gary B. (2012) System Analysis and Design, Language Learning

9) Stair, Ralph M. (2012) definition of information Retrieved from the book: Information Systems Essentials, Language Learning Asia Pte.Ltd.

10) Suleiman Uma

Abdullahi,

U.S.

(2015)CITIZENS

REGISTRATION

MANAGEMENT SYSTEMRetrievedfromhttps://www.scribd.com/doc/49162007/CITIZENS-REGISTRATION-MANAGEMENT-SYSTEMChapter-One 


\section{Senior Citizen information System}

11) The Power of Text Message Marketing [INFOGRAPHIC] - MashableRetrieved fromhttps://mashable.com/2012/07/13/ text-message-marketing-infographic/

12) William, Baltazar P. (2016) senior citizens Retrieved from the book: Fundamentals of Accounting Manila: Mindshapers Co.,Inc.

13) Zarate, Cynthia A. (2016) Organization and Management Retrieved from the book, high school, Quezon City: $\mathrm{C}$ and $\mathrm{E}$ Publishong Inc. 